\title{
Estudo comparativo do uso de coagulante à base de sementes de Moringa oleifera Lam. e sulfato de alumínio no tratamento físico e químico de efluente de laticínio
}

\section{Izabela Gouveia Nascimento ${ }^{1}$ e Fabio de Melo Resende ${ }^{2}$}

\author{
${ }^{1}$ Universidade Federal de Sergipe. Curso de Graduação em Agroindústria.. Campus \\ do Sertão. Nossa Senhora da Glória-SE, Brasil (CEP 49680-000). E-mail: \\ izabelagouveia@outlook.com. \\ ${ }^{2}$ Universidade Federal de Sergipe. Núcleo de Graduação da Agroindústria \\ (NEAGROS). Campus do Sertão. Nossa Senhora da Glória-SE, Brasil \\ (CEP 49680-000).
}

Resumo. 0 presente trabalho objetivou avaliar a influência de diferentes tipos de coagulantes no processo de coagulação/ floculação aplicados no tratamento físico e químico de efluente oriundo de agroindústria de laticínios. Para isso, fez-se uso de sementes de moringa em pó, extratos aquosos e salinos com e sem óleo e o agente químico sulfato de alumínio. Os ensaios experimentais foram realizados em duplicata em Jar Test, usando um litro de efluente para cada ensaio, com temperatura, velocidade e tempo de rotação pré-estabelecidos. Ao final dos ensaios foram retiradas alíquotas de cada amostra para análise de parâmetros de condições e padrões de lançamento de efluentes estabelecidos pelas Resoluções CONAMA no 357/2005 e no $430 / 2011, \mathrm{pH}$, cor aparente e turbidez. Com os resultados alcançados na caracterização dos experimentos, aplicou-se análise estatística, onde os valores de eficiência, $\mathrm{pH}$, cor aparente e turbidez foram submetidos à análise de variância comparando as médias por meio do teste de Tukey a $5 \%$ de significância. Ao final, conclui-se que o uso de coagulantes extraídos a partir das sementes de Moringa oleifera Lam. mostrou-se uma fonte alternativa sustentável para uso no tratamento físico e químico de efluente de agroindústria de laticínios, podendo, futuramente, com o aprimoramento das técnicas, vir a ser usado de maneira complementar ou a substituir o sulfato de alumínio.

Palavras-chave: Legislação; Moringa; Sulfato de alumínio; Tratamento de efluentes.

Abstract. Comparative study of the use of Moringa oleifera Lam. seed-based coagulant and aluminum sulfate in the physical-chemical treatment of dairy effluent. The present work aims to evaluate the influence of different types of coagulants in the coagulation/flocculation process, using the

Recebido

$02 / 01 / 2020$

Aceito

$12 / 04 / 2020$

Disponível on line

$13 / 04 / 2020$

Publicado

$30 / 04 / 2020$

Acesso aberto

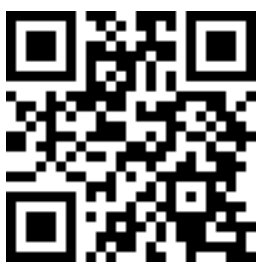

D 0000-0002-3985-755X

Izabela Gouveia

Nascimento

D) 0000-0002-9018-7176

Fabio de Melo Resende

ISSN 2359-1412/RBGAS-2020-0001/2020/7/15/8/97

Rev. Bras. Gest. Amb. Sustent.

http://revista.ecogestaobrasil.net 
physicochemical treatment of the effluent from the dairy agribusiness. For this, it made use of moringa seeds powder, aqueous and saline extracts with and without oil and with the chemical agent aluminum sulfate. Experimental assays were performed in duplicate in the Jar Test, using one liter of effluent for each assay, with predetermined temperature, velocity and rotation time. At the end of the tests, samples were taken from each sample for analysis of effluent release conditions and patterns, applied by CONAMA's Resolutions 357/2005 and $430 / 2011, \mathrm{pH}$, apparent color and turbidity. With the results achieved in the characterization of the experiments, where statistical analysis is applied, where the values of efficiency, $\mathrm{pH}$, apparent color and turbidity were analyzed by analysis of variance compared as media by Tukey test at $5 \%$ significance. In the end, conclude the use of coagulants extracted from Moringa oleifera Lam seeds. Has shown a sustainable alternative source for use in the physical-chemical treatment of dairy agroindustrial effluents, allowing for future or improved techniques to be used in a timely manner supplement or replace aluminum sulphate.

Keywords: Legislation; Drumstick tree; Aluminum sulfate; Wastewater treatment.

\section{Introdução}

A disponibilidade de água doce é um dos grandes problemas enfrentados hoje, isso porque, além, da grande demanda requerida para a agricultura, indústria e abastecimento das cidades, parte da água usada está sendo eliminada sem qualquer tratamento específico (Barbosa e Molina, 2011). Devido aos diversos usos diretos e indiretos dos recursos hídricos em atividades industriais, surge à necessidade de sua preservação e recuperação, algo que já vem ocorrendo e tornando-se mais evidente a cada dia. A poluição dos corpos de água tornou-se um problema mundial e seu controle é o maior desafio da gestão dos recursos hídricos, tanto no Brasil como no mundo (Teodoro et al., 2013).

Maldaner (2008) afirma que toda vez que um resíduo industrial for gerado é necessário que exista uma alternativa para o seu tratamento, pois este não deve ser acumulado indefinidamente em um determinado local e muito menos ter seus resíduos disseminados no meio ambiente de qualquer maneira.

Wissmann et al. (2012) apontam para o despertar das indústrias em relação a questão ambiental, surgindo primeiro da necessidade de adequação dos meios de produção as exigências feitas pelos órgãos de fiscalização em detrimento as penalidades previstas nas leis ambientais vigentes. De encontro a essa realidade, as indústrias de laticínios, responsáveis pela geração e alta demanda de efluentes contendo uma elevada carga orgânica, juntamente com os resíduos sólidos provenientes das plantas de processamento, viram a necessidade da aplicação de melhorias que possibilitassem a redução dos impactos diretos causados ao meio ambiente.

As indústrias são obrigadas a adotarem o uso de tecnologias mais limpas e eficientes em seus processos produtivos, sendo assim, é de suma importância fornecer uma destinação adequada a todo e qualquer resíduo - seja ele sólido ou líquido - gerado, garantindo, assim, a manutenção do meio ambiente. Partindo desta premissa, há tempos, fontes alternativas de tratamento para os mais diversos tipos de efluentes vêm sendo estudadas e testadas, principalmente, o uso de agentes coagulantes/floculantes naturais 
biodegradáveis e de baixo custo em substituição, ou como um complemento, aos agentes químicos usualmente utilizados. Dentre eles, encontra-se a Moringa oleifera Lam., planta de origem indiana presente no semiárido sergipano, que promove, por meio de suas proteínas catiônicas, a coagulação e clarificação de águas.

Assim, o presente trabalho objetivou avaliar a influência de diferentes tipos de coagulantes no processo de coagulação/floculação aplicados no tratamento físico-químico de efluente de laticínios.

\section{Metodologia}

Os ensaios foram realizados em duas etapas e lugares diferentes, entre o final do ano de 2018 e início de 2019, a produção dos coagulantes naturais (etapa I) ocorreu no Laboratório de Bromatologia, do Instituto Tecnológico e de Pesquisas do Estado de Sergipe (ITPS), enquanto os ensaios em Jar Test (etapa II) foram realizados no Laboratório do Núcleo de Petróleo, Gás e Biocombustíveis (NUPEG), da Universidade Federal de Sergipe, Campus São Cristóvão. 0 efluente utilizado para a realização dos experimentos foi adquirido em agroindústria de produtos lácteos, situada no Município de Nossa Senhora da Glória, Estado de Sergipe, Nordeste do Brasil.

\section{Preparo dos coagulantes à base de sementes de Moringa oleifera Lam.}

Para o preparo dos agentes coagulantes naturais, as sementes secas e sem as cascas da moringa foram previamente trituradas até a obtenção do pó. Em seguida, pesouse 2 g para o preparo dos extratos aquosos e salinos, com e sem óleo.

Para o preparo do extrato de moringa com óleo em meio aquoso, adicionou-se em um béquer $1,0 \mathrm{~g}$ de torta de moringa e $50 \mathrm{~mL}$ de água destilada, já em meio salino, adicionou-se em um béquer $1,0 \mathrm{~g}$ de torta de moringa e $50 \mathrm{~mL}$ de solução salina de $\mathrm{NaCl}$ a $1,0 \mathrm{~mol} / \mathrm{L}$. Em seguida, a solução foi homogeneizada durante 30 min por um misturador a uma rotação de $1.000 \mathrm{rpm}$. Por fim, as misturas obtidas foram separadas por meio de filtração a vácuo, em que os filtrados obtidos foram, respectivamente, o extrato de moringa com óleo em meio aquoso e o extrato de moringa com óleo em meio salino (adaptado de Araújo et al., 2011; Miranda et al., 2011; Sousa et al., 2018).

0 óleo contido nas sementes foi extraído através do sistema de extração usando Soxhlet e éter etílico P.A., onde foram pesados 2,0 g da massa da moringa em pó em pesa filtro com papel filtro e levados à estufa, à temperatura de $105^{\circ} \mathrm{C}$, durante $30 \mathrm{~min}$. $\mathrm{A}$ seguir, preparou-se o cartucho para ser adicionado ao Soxhlet para extração do óleo. Após $6 \mathrm{~h}$ de extração, o cartucho foi retirado do aparelho extrator e levado à estufa a $105^{\circ} \mathrm{C}$, durante $1 \mathrm{~h}$. Após seco, retirou-se a amostra do cartucho, repetiu-se a metodologia acima para preparo de extratos aquoso e salino, porém, desta vez, sem óleo.

\section{Ensaios de coagulação/floculação realizados em Jar Test}

Para a realização dos ensaios, utilizou-se um litro de efluente para cada tratamento. Os ensaios foram realizados a temperatura ambiente entre $28{ }^{\circ} \mathrm{C}$ e $29^{\circ} \mathrm{C}$, mantendo-se as mesmas condições de pressão e temperatura durante todo o processo. 0 $\mathrm{pH}$ do efluente estava em 4,0. 0 tempo e velocidade de rotação em Jar Test ficaram definidas em velocidade rápida de $160 \mathrm{rpm}$, durante $5 \mathrm{~min}$, e velocidade lenta de $20 \mathrm{rpm}$, durante $15 \mathrm{~min}$, com repouso de $2 \mathrm{~h}$ para ação dos coagulantes.

Devido ao aparelho Jar Test possuir capacidade para seis jarras, para otimizar o processo de ensaios, foram realizados dois por vez. Sendo assim, primeiramente, foram-se medidos os pHs das amostras do efluente de laticínio, como os agentes coagulantes atuam melhor em meio alcalino, fez-se necessário correção utilizando $2 \mathrm{~g}$ da solução de $\mathrm{NaOH}$ até que atingisse uma faixa entre 9,0 e 10,0, em seguida, foram adicionados os coagulantes. Após os processos de homogeneização rápida, promovendo a coagulação, e 
homogeneização lenta, promovendo a floculação, seguiu-se a etapa de repouso das amostras, para a decantação das partículas suspensas. Após o período de repouso, ocorreu a medição dos pHs finais dos tratamentos e os sobrenadantes foram retirados, ficando ao fundo dos jarros do Jar Test apenas o lodo residual que foi descartado em seguida.

Ao final dos ensaios, os dados obtidos foram quantificados e tabulados. De cada amostra foram retiradas alíquotas para determinação dos parâmetros de cor aparente através de método espectrofotométrico, utilizando espectrofotômetro de absorção molecular UV-VIS a $456 \mathrm{~nm}$, turbidez através de Turbidímetro DM-TU, de acordo com o "Standard Methods (APHA, 2017) e análises de absorbância em espectrofotômetro 800Xi a $680 \mathrm{~nm}$.

Por conseguinte, a tabulação dos dados obtidos seguiu-se a etapa de cálculo das medias de absorbância, por meio da Equação 1, para avaliação da eficiência dos tratamentos aplicados ao efluente de laticínio com os diferentes tipos de coagulantes.

$$
\% \mathrm{Ef}=\left(\frac{A b s i-A b s f}{A b s i}\right) \times 100 \%
$$

Onde:

$\mathrm{Abs}_{\mathrm{i}}=$ Absorbância inicial (efluente bruto).

$\mathrm{Abs}_{\mathrm{f}}=$ Absorbância final (tratamentos).

\section{Análise dos dados}

Para esta pesquisa fez-se uso do Delineamento Inteiramente Casualizado (DIC), onde os dados obtidos foram submetidos a avaliações estatísticas para análises físicas e químicas dos seus tratamentos (coagulantes/floculantes), na qual os resultados foram analisados por meio de Análise de Variância (ANOVA) e teste de média de Tukey ao nível de 5\% de significância pelo programa Sisvar ${ }^{\circledR}$.

\section{Resultados e discussão}

0 processamento dos produtos lácteos, em geral, envolve diversos compostos e/ou substâncias como carboidratos, sais minerais, vitaminas e água (Machado et al., 2002). A quantidade de resíduo gerado no beneficiamento lácteo pode variar de 1 a 5 vezes o volume de leite processado, dependendo, no entanto, do produto a ser elaborado e do nível de automação das indústrias de laticínios (Matos, 2010).

Os efluentes deste tipo de indústria possuem em sua constituição, principalmente, leite diluído e materiais sólidos (oriundos das etapas de processamento), além da presença de agentes químicos de limpeza (da água de lavagem de pisos, equipamentos, tubulações e demais instalações da indústria), açúcar, pedaços de frutas (do processamento de iogurte), essências e diversos condimentos (do processamento de queijos e manteigas). Em muitos laticínios, o soro não reaproveitado para a produção de subprodutos, acaba sendo também diluído e descartado com os demais efluentes líquidos gerados, porém, o soro do leite possui uma capacidade poluidora, o que é considerado um grave fator de poluição (Magno, 2010; Silva, 2011; Pokrywiecki, 2013).

Diante da importância da cadeia produtiva de leite e derivados, surgem problemas voltados aos aspectos ambientais principalmente, pois as indústrias produzem quantidades relativamente grandes de efluentes líquidos e estes, por sua vez, estão entre 
os mais agressivos devido ao alto teor de matéria orgânica que possuem (Saraiva, 2008; Amorim, 2014).

Toda indústria de laticínios, sem exceções, gera resíduos do tipo líquido e sólido, além de emissões atmosféricas capazes de causar graves impactos ao meio ambiente. Por isso, a lei ambiental vigente requer que as indústrias tratem seus resíduos de maneira adequada. Uma das alternativas é controlando os processos e buscando alternativas para a reutilização destes resíduos, de forma a reduzir custos com tratamento e disposição final (Silva, 2011). Para conseguir êxito no processo de gerenciamento desses resíduos é fundamental que a empresa conheça os tipos de resíduos que são gerados, suas características e fontes de geração (Buss e Henkes, 2015).

De acordo com Silva (2011), mais conhecidos como efluentes industriais, os resíduos líquidos oriundos da indústria de laticínios, é considerado como um dos principais responsáveis pela poluição causada por este segmento.

A poluição provocada por esse efluente é tamanha e se dá, principalmente, em razão do elevado teor de carga de matéria orgânica - responsável principal por problemas de poluição das águas -, podendo ocasionar poluição no solo, de maneira a comprometer sua estrutura físico-química, poluição dos mananciais, provocando a geração de odores desagradáveis, podendo ainda contribuir com a intensificação do processo de eutrofização dos mesmos, sobretudo no ambiente aquático com ausência ou pouca ocorrência de correntezas (Costa et al., 2014).

\section{Legislação ambiental}

O lançamento de resíduos líquidos nos corpos receptores deverá obedecer aos limites estabelecidos de acordo com as condições da qualidade da água, conforme sua classe de padrões de lançamento de efluentes (Nunes, 2008). Desta forma, o Conselho Nacional do Meio Ambiente (CONAMA), por meio da Resolução no 357/2005, além de classificar os corpos d'água e dar as diretrizes ambientais para o seu enquadramento, estabelece as condições e padrões de lançamento de efluentes com limites individuais para cada substância, e dá outras providências (Brasil, 2005). Subsequentemente, a Resolução CONAMA no 430/2011, dispõe sobre condições, parâmetros, padrões e diretrizes para gestão do lançamento de efluentes em corpos de água receptores, onde altera parcialmente e complementa a Resolução no 357/2005 (Brasil, 2011).

A Resolução CONAMA no 430/2011 traz, de maneira explícita, em seu art. 3o que os efluentes de qualquer fonte poluidora somente poderão ser lançados diretamente nos corpos receptores após serem submetidos a um devido tratamento e que obedeçam às condições, padrões e exigências dispostas tanto em leis quanto em outras normas aplicáveis. E complementa logo a seguir, em seu parágrafo único, que o órgão ambiental competente poderá, a qualquer momento, mediante fundamentação técnica acrescentar outras condições e padrões para o lançamento de efluentes, ou torná-los mais restritivos, levando em consideração as condições do corpo receptor, ou exigir o uso de tecnologia ambientalmente adequada e economicamente viável para o tratamento dos efluentes que seja compatível com as condições do respectivo corpo receptor (Brasil, 2011).

\section{Moringa oleifera Lam.}

A moringa, planta de múltiplos usos, vem se difundindo ao longo dos anos nos mais variados continentes em virtude de sua capacidade de adaptação aos climas quentes e secos e pela sua utilização em diversos setores da vida humana tais como alimentação, indústria farmacêutica, produção de óleo, como planta ornamental e melífera, fonte de proteína para os animais e na clarificação de águas turvas onde as espécies Moringa oleifera e Moringa stenopetala possuem um maior destacam no gênero como um dos coagulantes naturais mais importantes e promissores (Silva et al., 2018; 0jo, 2019). 
Em função da necessidade de obter métodos alternativos mais baratos e eficazes para o tratamento da água (Rangel, 2011; Andrade e Gorlach-Lira, 2018), a moringa tem sido alvo de muitas pesquisas devido as propriedades coagulantes presentes em suas sementes, propriedades essas atribuídas as proteínas catiônicas de baixo peso molecular que, ao interagirem com o material orgânico presente na água, provocam uma instabilidade coloidal, promovendo sua remoção de maneira mais fácil por meio do processo de sedimentação. Em função disso, o extrato das sementes de moringa vem sendo utilizado de forma muito bem-sucedida em processos de clarificação de águas turvas para consumo humano, substituindo, inclusive, o sulfato de alumínio, comumente utilizado para este fim (Muybi e Evison, 1995; Makkar e Becker, 1997; Ndabigengesere e Narasiah, 1998; Matos, 1998).

\section{Sulfato de alumínio}

$\mathrm{O}$ sulfato de alumínio $\left(\mathrm{Al}_{2}\left(\mathrm{SO}_{4}\right)_{3} \cdot \mathrm{H}_{2} \mathrm{O}\right)$ é um coagulante amplamente conhecido dada a sua grande utilização em ETA's e ETE's para o tratamento de água potável e efluentes em geral. Essa notoriedade se dá devido a facilidade de transporte deste agente, do seu baixo custo e boa eficiência na etapa de coagulação das partículas coloidais. No entanto, por ser um reagente químico não biodegradável, dependendo da concentração em que estiver presente na água, pode acarretar sérios riscos à saúde humana (Carvalho, 2008).

Os sais de alumínio são amplamente utilizados em todo o mundo como agente coagulante (Vaz, 2009). A coagulação com este agente químico é, geralmente, efetiva estando o pH numa faixa entre 5,0 a 8,0 (Vaz, 2009).

\section{Estudo comparativo}

Na Tabela 1 encontram-se listados os parâmetros quantitativos de qualidade avaliados, bem como suas respectivas relações de conformidade estabelecidos pelo CONAMA, comparando os resultados obtidos neste estudo com os limites fixados pela Resolução CONAMA no 357/2005 (Brasil, 2005) e pela Resolução no 430/2011 (Brasil, 2011).

Tabela 1. Limites de parâmetros monitorados segundo o CONAMA versus os parâmetros analisados.

\begin{tabular}{l|c|c|c|c|c|c|c}
\hline $\begin{array}{l}\text { Parâmetros } \\
\text { de qualidade }\end{array}$ & $\begin{array}{c}\text { Resolução no } \\
\mathbf{3 5 7 / 2 0 0 5} \text { e } \\
\text { Resolução no } \\
\mathbf{4 3 0 / 2 0 1 1}\end{array}$ & $\begin{array}{c}\text { Extrato } \\
\text { aquoso } \\
\text { c/ óleo }\end{array}$ & $\begin{array}{c}\text { Extrato } \\
\text { salino } \\
\text { c/ óleo }\end{array}$ & $\begin{array}{c}\text { Extrato } \\
\text { aquoso } \\
\text { s/ óleo }\end{array}$ & $\begin{array}{c}\text { Extrato } \\
\text { salino } \\
\text { s/ óleo }\end{array}$ & $\begin{array}{c}\text { Moringa } \\
\text { em pó }\end{array}$ & $\begin{array}{c}\text { Sulfato de } \\
\text { alumínio }\end{array}$ \\
\hline $\mathrm{pH}$ & 6 a 9 & 10 & 8 & 8,3 & 9,6 & 9,3 & 10 \\
\hline Cor aparente & $\leq 75$ & 0,7310 & 1,1773 & 1,5066 & 1,2361 & 1,6768 & 0,4343 \\
\hline Turbidez & $\leq 100$ & 637,00 & 632,50 & 730,00 & 397,00 & 639,50 & 83,90 \\
\hline
\end{tabular}

Os resultados alcançados na caracterização dos experimentos, os dados de eficiência, $\mathrm{pH}$, cor aparente e turbidez foram submetidos à ANOVA, onde, as médias foram comparadas utilizando o teste de Tukey a 5\% de significância (Tabela 2). 
Tabela 2. Análise de variância, expressos em média, para as variáveis físicas e químicas de eficiência (absorbância), pH, cor aparente e turbidez para os tratamentos.

\begin{tabular}{lcccc}
\hline Tratamento & Eficiência/Absorbância & pH & Cor aparente & Turbidez \\
\hline Extrato aquoso com óleo & $59,66^{\mathrm{a}}$ & $10,0^{\mathrm{b}}$ & $0,7310^{\mathrm{ab}}$ & $700,00^{\mathrm{b}}$ \\
Extrato salino com óleo & $64,09^{\mathrm{a}}$ & $10,0^{\mathrm{b}}$ & $1,1773^{\mathrm{abc}}$ & $400,00^{\mathrm{ab}}$ \\
Extrato aquoso sem óleo & $50,41^{\mathrm{a}}$ & $9,0^{\mathrm{b}}$ & $1,5066^{\mathrm{bc}}$ & $730,00^{\mathrm{b}}$ \\
Extrato salino sem óleo & $61,75^{\mathrm{a}}$ & $9,5^{\mathrm{b}}$ & $1,2361^{\mathrm{bc}}$ & $259,00^{\mathrm{a}}$ \\
Semente em pó & $46,10^{\mathrm{a}}$ & $10,0^{\mathrm{b}}$ & $1,6768^{\mathrm{c}}$ & $722,00^{\mathrm{b}}$ \\
Sulfato de alumínio & $85,71^{\mathrm{a}}$ & $7,0^{\mathrm{a}}$ & $0,4343^{\mathrm{a}}$ & $53,00^{\mathrm{a}}$ \\
\hline
\end{tabular}

Médias seguidas pela mesma letra na coluna não diferem estatisticamente a $5 \%$ de probabilidade do teste de Tukey.

\section{pH}

Trata-se de uma variável importante e deve ser acompanhado para otimizar os processos de tratamento. As etapas de coagulação e floculação em que a água é submetida dentro de uma estação de tratamento é um processo dependente do $\mathrm{pH}$ (Baird, 2002).

0 pH ficou numa faixa entre 7,0 e 10,0 de atuação, porém, o extrato aquoso sem óleo e o extrato salino sem óleo apresentaram melhores resultados finais para o efluente tratado. Contudo, a variação de pH é normal, e, por atuar em diversos equilíbrios químicos provocados de maneira natural ou por meio de processos unitários de tratamento de águas, o pH é um parâmetro muito importante em diversos estudos realizados, principalmente pelas etapas de coagulação e floculação dependerem dele (Piveli, 2001) para que haja uma ótima ação do coagulante aplicado.

Para um melhor vislumbre da eficácia dos tratamentos usando agentes coagulantes naturais, à base de sementes de Moringa oleifera Lam., e químicos, com sulfato de alumínio, foram-se gerados gráficos quanto aos parâmetros de $\mathrm{pH}$, cor aparente e turbidez avaliados comparando-os aos limites estabelecidos pela Resolução CONAMA no 357/2005 e pela Resolução CONAMA no 430/2011 (Tabela 2).

A Figura 1 mostra o comportamento do $\mathrm{pH}$ após o tratamento físico-químico usando diferentes tipos de coagulantes nos ensaios realizados em Jar Test.

10

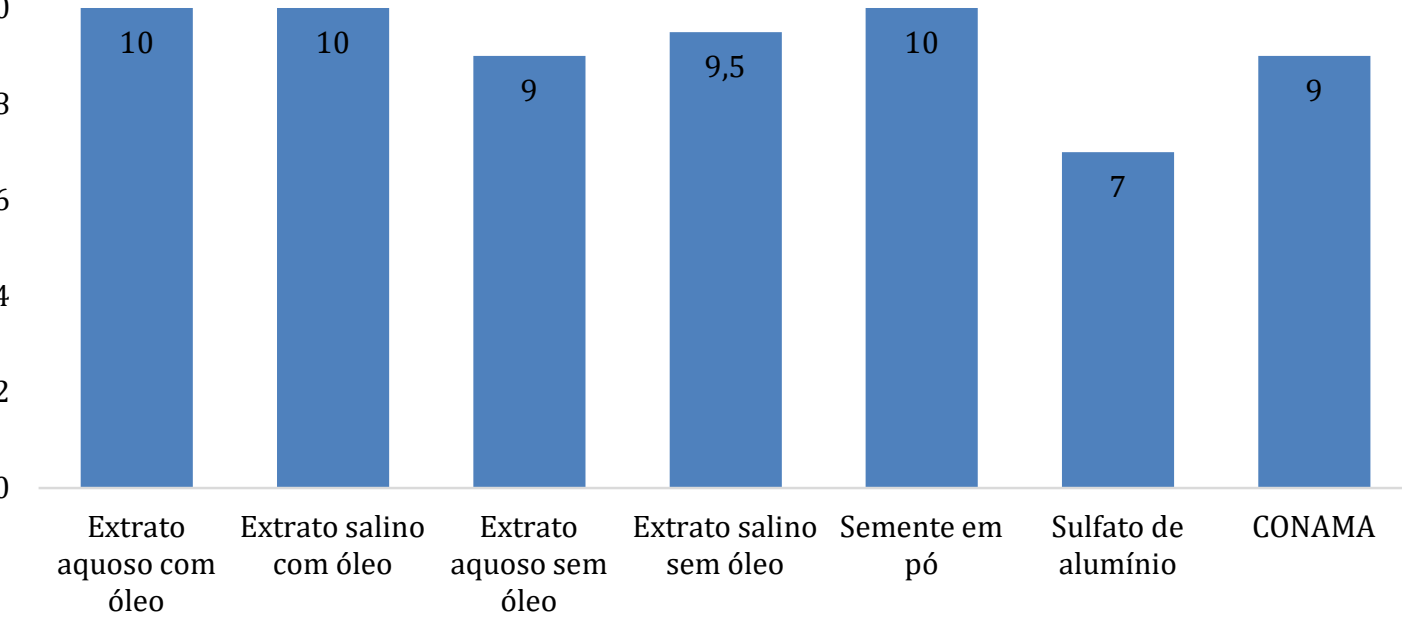

Figura 1. pH analisado para cada tratamento versus Resolução CONAMA. 
$\mathrm{O}$ pH do efluente bruto de laticínio 4,0, após correção com $2 \mathrm{~g}$ de solução de $\mathrm{NaOH}$, ficou numa faixa entre 9 e 10. Subsequente ao tratamento - utilizando as sementes da moringa em forma de extratos salinos e aquosos com e sem óleo, em forma de pó e o sulfato de alumínio -, os valores de pH oscilaram entre 7 e 10.

De acordo com o CONAMA, os limites de $\mathrm{pH}$ para lançamento de efluentes em corpos d'água devem estar entre 6 e 9, sendo assim, apenas os tratamentos utilizando extrato aquoso com óleo e extrato salino sem óleo estariam dentro destes limites e aptos a serem despejados nos corpos receptores sem agredir ao meio ambiente.

\section{Cor aparente}

A cor na água pode derivar da presença de íons metálicos, principalmente, ferro e manganês; também de plâncton, algas, húmus e taninos (oriundos da decomposição da matéria orgânica), podendo ou não apresentar toxicidade quando a água é de origem industrial. A cor da água depende do pH da mesma e aumenta com a elevação deste (Von Sperling, 1996; APHA, 2017). É uma variável muito utilizada na caracterização de águas de abastecimento brutas e tratadas (Von Sperling, 1996), bem como na caracterização de efluentes agroindustriais.

A cor aparente de todos os tratamentos apresentara bom desempenho. A eficiência de redução substancial de cor usando extrato aquoso, oriundo de sementes de Moringa oleifera Lam., no tratamento de água para consumo humano foi comprovada por Scuracchio (2010), que evidenciou também redução de turbidez e a existência, praticamente, de particulado no sobrenadante ao final do tratamento. Caldeira (2012) confirma a existência de pesquisas que descrevem o potencial da moringa no tratamento de água, apresentando resultados satisfatórios na redução da turbidez. No entanto, em questão de turbidez, todos os resultados obtidos por meio dos experimentos em Jar Test foram considerados iguais estatisticamente.

Ao avaliar a Resolução CONAMA no 357/2005, o efluente de laticínio devidamente tratado se enquadra como água doce de classe 2 que pode ser destinada ao abastecimento para consumo humano, após passar por tratamento convencional; à proteção das comunidades aquáticas; à recreação de contato primário, conforme Resolução CONAMA no 274/2000 (Brasil, 2000); à irrigação de hortaliças, plantas frutíferas e de parques, jardins, campos de esporte e lazer, com os quais o público possa vir a ter contato direto; e à aquicultura e atividade de pesca (Brasil, 2005).

A Figura 2 representa os percentuais de remoção da cor aparente em relação ao que delimita o CONAMA.

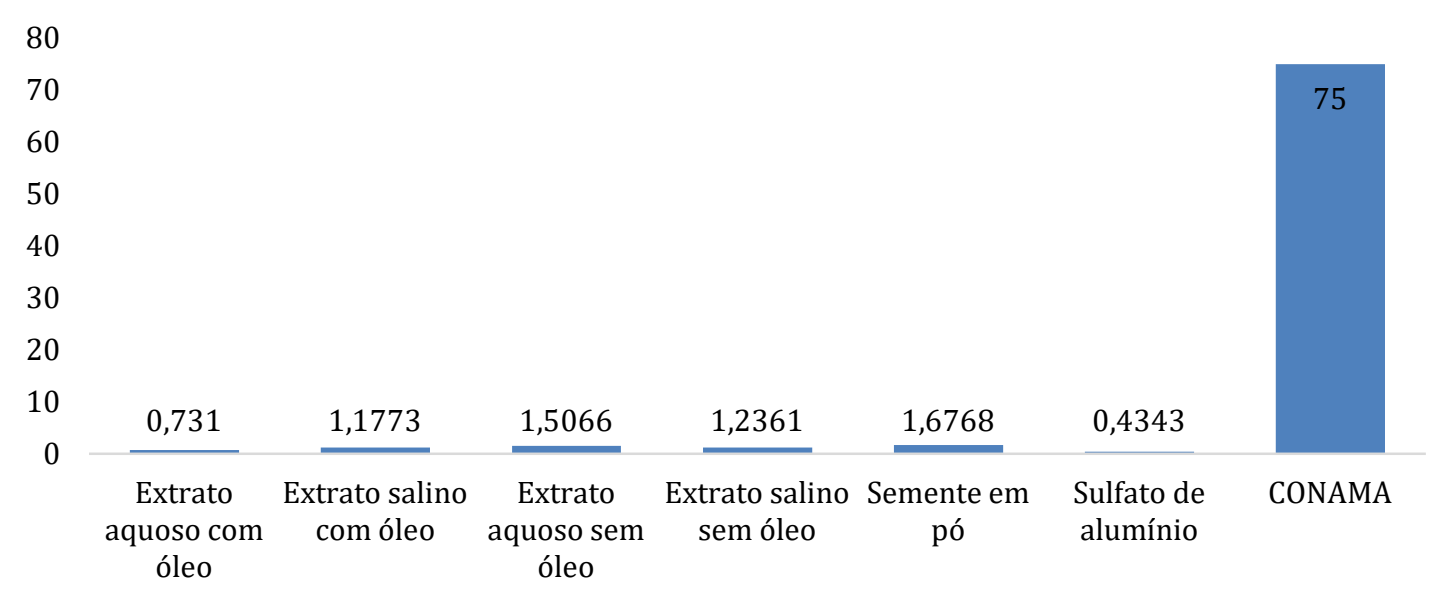

Figura 3. Cor aparente analisada para cada tratamento versus Resolução CONAMA. 
Inicialmente, o efluente bruto de laticínio apresentava coloração aparente de 2,6309 mgPt/L, após as etapas do tratamento físico-químico os índices de remoção desta demonstraram um bom desempenho dos agentes coagulantes. Assim, com base no que estabelece o CONAMA, o limite de cor para o lançamento de efluentes em corpos d'água deve ser menor igual a $75 \mathrm{mgPt} / \mathrm{L}$, portanto, todos os tratamentos se enquadraram dentro destes limites.

Os padrões de lançamento de cor do efluente de laticínio foram avaliados de maneira diferente do que rege o CONAMA. Nesta pesquisa, tal como explica Martins (2014) em seu estudo, foi-se avaliada a cor aparente do efluente, uma vez que a Resolução CONAMA no 357/2005 avalia a cor verdadeira para o controle da emissão de efluentes em corpos hídricos, porém, considerando que, obrigatoriamente, a cor verdadeira é inferior a cor aparente devido a metodologia de obtenção destes parâmetros, ainda assim é possível fazer uma comparação entre estes parâmetros.

\section{Turbidez}

Quanto à turbidez dos efluentes, a Figura 4 representa o percentual de remoção da turbidez em relação ao que delimita o CONAMA. Diferentemente do que houve com a cor aparente, neste quesito, apenas o tratamento utilizando o agente coagulante químico sulfato de alumínio se enquadrou ao que estabelece o órgão ambiental, ou seja, este foi o único cujo resultado encontra-se na faixa de menor igual a $100 \mathrm{mg} / \mathrm{L}$.

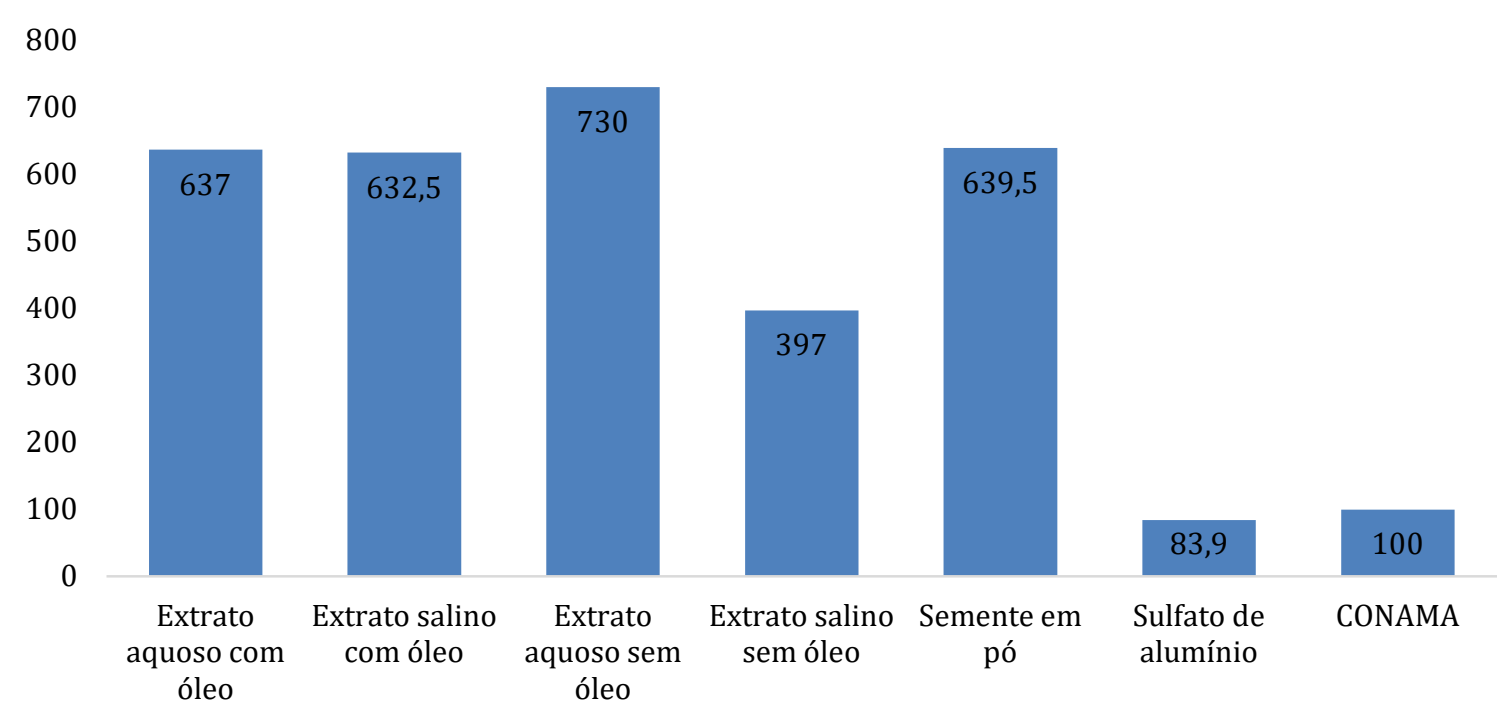

Figura 4. Variável turbidez analisado para cada tratamento versus Resolução CONAMA.

Analisando a eficiência dos tratamentos aplicados ao efluente de laticínio utilizando diferentes tipos de coagulantes/floculantes, em questão de eficiência por meio de análise de absorbância, os tratamentos à base de sementes de Moringa oleifera Lam. foram considerados satisfatórios apenas para os extratos aquosos e salinos com e sem óleo quando comparados aos resultados com o uso do sulfato de alumínio, tendo em vista que o sulfato de alumínio é o coagulante mais utilizado, devido à excelente formação do floco (Carvalho, 2008). 


\section{Considerações finais}

Concluiu-se com esta pesquisa que o uso de coagulantes naturais extraídos a partir das sementes secas e trituradas da Moringa oleifera Lam. mostrou-se como uma fonte alternativa sustentável para uso experimental no tratamento físico-químico de efluente de laticínio, podendo, futuramente, com o aprimoramento das técnicas de uso, vir a ser usado de maneira complementar ou a substituir o sulfato de alumínio, que é o mais comumente utilizado para este fim. Os resultados obtidos por meio dos ensaios realizados em Jar Test demostraram potencial satisfatório quanto ao uso dos extratos aquosos e salinos com e sem óleo quando comparados aos resultados com o uso do sulfato de alumínio em questão de eficácia dos tratamentos aplicados ao efluente de laticínio, utilizando diferentes tipos de agentes coagulantes por meio de análise de absorbância.

Quanto aos parâmetros de $\mathrm{pH}$, cor aparente e turbidez, avaliados de acordo com os padrões de lançamento de efluentes em corpos d'água regidos pelo CONAMA, estiveram dentro dos limites estabelecidos para $\mathrm{pH}$ apenas extrato aquoso com óleo e extrato salino sem óleo; para cor aparente todos se enquadraram, e para turbidez apena o sulfato de alumínio obteve um bom desempenho de remoção estando dentro dos limites regidos pela legislação ambiental.

Conclui-se também que a quantidade de lodo residual como corpo de fundo nos jarros gerado pelo agente coagulante químico fora maior quando comparada aos agentes coagulantes naturais.

\section{Conflito de interesses}

Os autores declaram não haver conflito de interesses.

\section{Referências}

Amorim, R. F. Tratamento de efluente em lagoas de estabilização: um estudo de caso em indústria de laticínio na região do Vale do Jamari-RO. Ariquemes: Fundação Universidade Federal de Rondônia. Ariquemes, 2014. (Monografia de graduação).

Andrade, T. M.; Gorlach-Lira, K. Antibacterial activity of the white lily Moringa oleifera seed extract and its use in water treatment. Brazilian Journal of Biological Sciences, v. 5, n. 11, p. 699-707, 2018. https://doi.org/10.21472/bjbs.051108

APHA - American Public Health Association. Standard methods for the examination of water and wastewater. 23. ed. Washington: APHA, 2017.

Araújo, N. A.; Rodrigues, R. S.; Moitinho, A.; Gomes, M. C. M.; Santana, C. R.; Silva, G. F. Eficiência dos extratos aquoso e salino de Moringa oleifera Lam. no tratamento do efluente gerado na produção de biodiesel. Anais do World Water Congress, 2011.

Baird, C. Química ambiental. 2 ed. Porto Alegre: Bookman, 2002.

Barbosa, F. A.; Molina, L. R. Conjuntura da carne bovina no mundo e no Brasil. AgroGushi, 2011. Disponível em: <https://www.agrogushi.com.br/conjuntura-da-carne-bovina-nomundo-e-no-brasil/>. Acesso em: 23 maio 2019.

Brasil. Resolução CONAMA no 274, de 25 de janeiro de 2000. Define os critérios de balneabilidade em águas brasileiras. Disponível em: <http://www2.mma.gov.br/port/conama/legiabre.cfm?codlegi=272>. Acesso em: 23 maio 2019. 
Brasil. Resolução CONAMA no 357, de 17 de março de 2005. Dispõe sobre a classificação dos corpos de água e diretrizes ambientais para o seu enquadramento, bem como estabelece as condições e padrões de lançamento de efluentes, e dá outras providências. Disponível em: <http://www2.mma.gov.br/port/conama/legiabre.cfm?codlegi=459>. Acesso em: 23 maio 2019.

Brasil. Resolução CONAMA no 430, de 13 de maio de 2011. Dispõe sobre condições e padrões de lançamento de efluentes, complementa e altera a Resolução no 357, de 17 de março de 2005, do Conselho Nacional do Meio Ambiente - Conama. Disponível em: <http://www2.mma.gov.br/port/conama/legiabre.cfm?codlegi=646>. Acesso em: 23 maio 2019.

Buss, D. A.; Henkes, J. A. Estudo dos impactos ambientais causados por laticínios com foco no reaproveitamento dos resíduos gerados. Revista Gestão \& Sustentabilidade Ambiental, v. 3, n. 2, p. 384-395, 2015. https://doi.org/10.19177/rgsa.v3e22014384-395

Caldeira, N. C. A. Avaliação da Moringa oleifera Lam. para remoção de dureza de águas. Montes Claros: Universidade Federal de Minas Gerais, 2012. (Monografia de graduação).

Carvalho, M. J. H. Uso de coagulantes naturais no processo de obtenção de água potável. Maringá: Universidade Estadual de Maringá, 2008. (Dissertação de mestrado).

Compri-Nardy, M.; Stella M. B.; Oliveira, C. Práticas de laboratório de Bioquímica e Biofísica. Rio de Janeiro: Guanabara Koogan, 2009.

Costa, G. H. G.; Masson, I. S.; Freita, L. A.; Roviero, J. P.; Mutton, M. J. R. Use of Moringa oleifera Lamarck leaf extract as sugarcane juice clarifier: Effects on clarifed juice and sugar. Food Science and Technology, v. 34, n. 1, 2014. https://doi.org/10.1590/S010120612014000100029

Machado, R. M. G.; Freire, V. H.; Silva, P. C.; Figuerêdo, D. V.; Ferreira, P. E. Controle ambiental nas pequenas e médias indústrias de laticínios: Projeto Minas Ambiente. Belo Horizonte: SEGRAC, 2002.

Magno, P. S. L. Tratamento de efluentes em lagoas de estabilização: um estudo de caso em indústria de laticínio. Taubaté: Universidade de Taubaté, 2010. (Dissertação de mestrado).

Makkar, H. P. S.; Becker, K. Nutrients and antiquality factors in different morphological parts of the Moringa oleifera tree. The Journal of Agricultural Science, v. 128, n. 3, p. 311-322, 1997. https://doi.org/10.1017/S0021859697004292

Maldaner, T. L. Levantamento das alternativas de minimização de impactos gerados pelos efluentes de abatedouros e frigoríficos. Brasília: UCB, 2008.

Martins, H. C. Estudo sobre os processos de coagulação, floculação e decantação em efluentes oriundos de usina canavieira. Londrina: Universidade Tecnológica Federal do Paraná, 2014. (Trabalho de Conclusão de Curso).

Matos, A. T.; Abrahão, S.; Monaco, P. A. L.; Sarmento, A. P.; Matos, M. P. Capacidade extratora de plantas em sistemas alagados utilizados no tratamento de águas residuárias de laticínios. Revista Brasileira de Engenharia Agrícola e Ambiental, v. 14, n. 12, p. 1311-1317, 2010. https://doi.org/10.1590/S1415-43662010001200009

Matos, F. J. A. Farmácias vivas: sistemas de utilização de plantas medicinais projetados para pequenas comunidades. 3. ed. Fortaleza: EUFC, 1998. 
Miranda, C. S. A.; Pereira, D. F.; Araújo, N. A.; Santos, T. M.; Cavalcanti, E. B.; Silva, G. F. Estudo da eficiência da semente e do extrato da moringa no tratamento de água produzida. Anais do VI Congresso Brasileiro de Pesquisa e Desenvolvimento em Petróleo e Gás, Florianópolis, 2011.

Muyibi, S. A.; Evison, L. M. Moringa oleifera seeds for softening hardwater. Water Research, v. 29, n. 4, p. 1099-1104, 1995. https://doi.org/10.1016/0043-1354(94)00250B

Ndabigengesere, A.; Narasiah, K. S. Quality of water treated by coagulation using Moringa $\begin{array}{llllll}\text { oleifera seeds. Water Research, v. 32, } & \text { n. 3, p.781-791, } 1998 .\end{array}$ https://doi.org/10.1016/S0043-1354(97)00295-9

Nunes, J. A. Tratamento físico-químico de águas residuárias industriais. 5. ed. Aracaju: Info Graphics, 2008.

Ojo, M. O. Evaluation of different nutritional and soil sources on the early growth of Moringa oleifera (Lam.). Revista Brasileira de Gestao Ambiental e Sustentabilidade, v. 6, n. 13, p. 549-555, 2019. https://doi.org/10.21438/rbgas.061322

Piveli, R. P.; Kato, M. T. Qualidade das águas e poluição: aspectos físico-químicos. 1. ed. São Paulo: Associação Brasileira de Engenharia Sanitária e Ambiental, 2006.

Pokrywiecki, T. S.; Gumy, M. P.; Tonial, I. B.; Pokrywiecki, J. C. Avaliação do processo de tratamento de efluentes de laticínios. Revista Acadêmica Ciência Animal, v. 2, n. 2, p. 93-101, 2013. https://doi.org/10.7213/academica.10.S01.A018

Rangel, M. S. Um purificador natural de água e um complemento alimentar para o Nordeste do Brasil. Aracaju: EMBRAPA Tabuleiros Costeiros, 2011.

Saraiva, C. B. Potencial poluidor de um laticínio de pequeno porte: um estudo de caso. Viçosa: Universidade Federal de Viçosa, 2008. (Dissertação de mestrado).

Scuracchio, P. A. Qualidade da água utilizada para consumo em escolas no Município de São Carlos-SP. Araraquara: Universidade Estadual Paulista, 2010. (Dissertação de mestrado).

Sieczka Junior, E. L. Estudo da alteração na absorção da luz monocromática (transmitância) como parâmetro de contaminação do mar por hidrocarbonetos. Curitiba: Universidade Tecnológica Federal do Paraná, 2013. (Dissertação de mestrado).

Silva, D. J. P. Resíduos na indústria de laticínios. Viçosa: Universidade Federal de Viçosa, 2011.

Silva, G. F.; Santana, M. F. S.; Lima, A. K. V. O.; Bergamasco, R.; Paiva, P. M. G.; Sant'Anna, M. C. S.; Serafini, M. R.; Bery, C. C. S. Potencialidades da Moringa oleifera Lam. São Cristóvão: Universidade Federal de Sergipe, 2018. v.4.

Sousa, A. J. S.; Fernandes, W. C. G.; Oliveira, E. L.; Marques, R. C. P. Tratamento de efluentes de oficinas automotivas para o reuso usando sementes de moringa. Anais do VI Congresso Internacional de Tecnologias para o Meio Ambiente, Bento Gonçalves, 2018.

Teodoro, A.; Ide, C. N.; Ribeiro, M. L.; Broch, S. A. O.; Silva, J. Implementação do conceito capacidade de diluição de efluentes no modelo de qualidade da água QUALUFMG: estudo de caso no Rio Taquarizinho (MS). Engenharia Sanitaria e Ambiental, v. 18, n. 3, 2013. https://doi.org/10.1590/S1413-41522013000300010

Vaz, L. G. L. Performance do processo de coagulação/floculação no tratamento de efluente líquido gerado na galvanoplastia. Toledo: Universidade Estadual do Oeste do Paraná, 2009. (Dissertação de mestrado). 
Von Sperling, M. Introdução à qualidade das águas e ao tratamento de esgotos. Belo Horizonte: Departamento de Engenharia Sanitária e Ambiental, 1996. v. 1.

Wissmann, M. A.; Hein, A. F.; Neuls, H. Geração de resíduos: uma análise da ecoeficiência nas linhas de produção em uma indústria de laticínios e a influência sobre os custos ambientais. Anais do VI Congresso Brasileiro de Custos, Curitiba, 2012. 